\title{
Correction to: Disability as Diversity
}

\author{
Lisa M. Meeks and Leslie Neal-Boylan
}

\section{Correction to: L. M. Meeks, L. Neal-Boylan (eds.), Disability as Diversity, https://doi.org/10.1007/978-3-030-46187-4}

The book was inadvertently published with an incorrect affiliation of Dr. Lisa M. Meeks in List of Contributors and in chapters 4, 5, 9, 10, 11 and 12. The affiliation is now updated as "Director of MDisability Education" throughout the book proof.

The updated versions of the chapters can be found at https://doi.org/10.1007/978-3-030-46187-4 https://doi.org/10.1007/978-3-030-46187-4_4 https://doi.org/10.1007/978-3-030-46187-4_5 https://doi.org/10.1007/978-3-030-46187-4_9 https://doi.org/10.1007/978-3-030-46187-4_10 https://doi.org/10.1007/978-3-030-46187-4_11 https://doi.org/10.1007/978-3-030-46187-4_12 